\title{
Market Entry Game Application in e-Commerce
}

\author{
Zheng Jianya, Li Weigang* \\ TransLab, Department of Computer Science, University of Brasilia, Campus Darcy Ribeiro, Brasilia-DF, Brazil. \\ *Corresponding author. Tel.: 5561 31073679; email: weigang@unb.br \\ Manuscript submitted February 16, 2016; accepted April 15, 2016. \\ doi: 10.17706/jsw.11.6.589-597
}

\begin{abstract}
Decision-making of market entry and incumbents defense is one of the most important issues in business activities as well as the research hotspot in academic community. This paper adopts game theory to study market-entry decisions of e-retailers in e-marketplace environment. All e-retailers are classified into two categories: one belongs to "giants" who have a great quantity of investments and aim to earn large profits. Another belongs to "dwarfs" who invest not so much and are less eager to make profit. To study the different characters between them and make entry decision in virtual business world, an e-commerce market entry game model is proposed. Using this model, a simulation of market entry decision is formed and a game tree is drawn to analyze the equilibrium. In addition to pure strategy equilibriums, the mixed strategy equilibriums are also analyzed to explore the probability of entrance into the market. Finally, through quantitative analyses, the proposed model demonstrates effective application for e-commerce context and meaningful advice for entrants to make entry or exit decision.
\end{abstract}

Key words: Differentiation, e-commerce, e-retailers, game theory, market entry decision.

\section{Introduction}

Market entry decision in an uncertain environment is not only an important issue in business field, but also a research hotspot in scientific community. Since market entry and exit decision was proposed by Dixit [1], it becomes an independent topic and attracts more and more researchers to dedicate in this area. Hopenhayn [2] developed a dynamic stochastic model for a competitive industry which endogenously determines processes for entering and exiting market as well as for individual firms' output and employment. Impullitti et al. [3] analyzed the market entry decision in export market and studied subsequent features when new firm successfully entered. Shen [4] constructed a dynamic model that features the stochastically and endogenously expanding demand of a new industry, and investigated the optimal entry and exit behavior of firms as the industry evolves. Gries et al. [5] used a real option model to analyze the tax influence in entrant decision making process, identified a set of neutral tax rates that preserve the post-tax investment and determine normal and paradoxical settings for investments to assist decision maker.

In past decades, game theory had grown vigorously as an efficient methodology to study the reactions when involves more than one participants. With this powerful tool, Selten and Guth [6] proposed a new class of game named "market entry game" to study the topic. Based on this concept, numerous researches proposed game model to expand the literature and stepped forward. Aguirregabiria and Suzuki [7] addressed a fundamental identification problem in the structural estimation of dynamic oligopoly models of market entering and exiting. A firm's profit function is defined by the fixed cost of an incumbent firm, 
entry cost of a new entrant and the scrap value of an existing firm. Rapoport [8] used an empirical experiment with many Ph.D students to investigate the group decision of market entry. The payoff depends on the quantity of entrants and the result experiment subjects adhered more strictly to pure strategies equilibrium. Zwick and Rapoport [9] inspected the equilibrium of market entry game by setting a commonly known limited number of entrants to guarantee profit. Surpass this number will lead to losses. In their works, they found out the parameters such as market capacity, entry fee, and method of subject assignment to groups which can significantly effect the equilibrium. Azevedo [10] mixed concepts from both game theory and real options theory, regarding decision making as a game to analyze the reactions between firms in market. Zheng et al. [11] studied the interrelation between e-retailers and e-marketplace provider, and concluded that the more effective way for platform providers is concentrating sales to less sellers and charge them for more service fees.

As e-commerce prospers in the age of internet, people could buy almost everything at home due to information revolution. E-commerce has changed human beings' lifestyle entirely because it helps people to cross the geographical barrier and save time from shopping in market in person. In such an explosion context, more and more retailers move their battlefield to the virtual world.

This paper is motivated to study the market entry decision from the retailer's perspective by adopting the game theory. An e-commerce market entry game model is built up to simulate the competition of e-commerce. The entrants choose to enter the market with low or high investment, according to the defined payoff function according to different strategies, the incumbents either fight or accommodate when entrants enter. Pure strategy equilibriums and mixed strategy equilibriums are investigated, and numerical experiments are conducted to verify the validation of proposed model. The results of numerical simulations demonstrate that for high investment entrants, incumbents are inclined to take the aggression strategy to defend the market; whereas for entrants with low investment, incumbents are benevolent to accommodate and share the market with them. For different scale of players, the model indicates different probability of entry respectively (Earn profit rather than loss). The effectiveness and correctness of e-commerce entry model could assist the decision-maker in the process of entering a new market.

\section{E-Commerce Market Entry Game Model}

In this section, the e-commerce market entry game model is defined to assist e-retailers to make market entering or exiting decision. The entry game [6] is a dynamic game of complete information, because players know the payoffs of each other for every possible outcome. There are two stages. In the first stage, the entrant has three possible actions, enter with low cost, enter with high cost, or do not enter. The action set of the incumbent is empty in the first stage, or equivalently, the only available action is "do nothing." Hence, only the entrant makes a move in the first stage. In the second stage, the action set of the incumbent contains two parts, be aggressive or accommodative. The entrant's only action in the second stage is "do nothing." In the second stage, the incumbent fully know the history of the game at first stage before making a decision, i.e., knowing the entrants' choices. To simplify the setup and analyze the model, this paper assumes that the game occurs between one existing incumbent and one entrant. The existing incumbent invests high cost in the market, while the entrant could choose to invest high or low capital in the market to compete with incumbent.

The definition of market entry game is that the manager of a firm is considering the possibility of entering a new market, where there is only one other firm operating. The manager's decision will be based on the profitability of the market, which in turn heavily depends on the reactions of the incumbent firm to the entry. The incumbent firm could be accommodative and let the entrant grab the market share or it could respond aggressively, competing with the entrant in a cut-throat price war. Another factor that 
affects the revenue stream is the investment level of the entering firm. The manager of the firm may invest either low cost or high cost. In this context, the market capacity of revenue is $r$, the low cost is $C_{l}$, high cost $C_{h}$. Also when the incumbent accommodates the giant entrant who makes a great investment, fierce competition would decrease the whole market profit, $\alpha$ is the parameter of competition, it could adjust the market profit when giant entrant enters into the market.

A game tree is drawn below to demonstrate the timing and payoff function for each player. At first, the entrant chooses strategies among three options, \{enter with high cost, enter with low cost, stay out . Then it is the incumbent's turn to observe the entrant's action and make a reaction either aggressive or accommodative. In the end, both participants involved take the payoff by the defined payoff function. The payoff functions for each player are revealed below:

a) As the first branch of game tree (Fig. 1) shows, when the entrant chooses to enter with high cost, there are two options for the incumbent: 1) Aggressive. The cost of the incumbent choosing to be aggressive equals to the investment of the entrant, namely using the original revenue of market $r$ to subtract the investment of entrant $C_{h}$; 2) Accommodation. While if the incumbent choose to be accommodative, then the new entrant could enter into the market and intensify the competition, $\alpha(\alpha \leq 1)$ is defined as an adjusting parameter for the profitability of market. The profit should be shared evenly between these two firms, which is $\left(\alpha^{*} r / 2, \alpha^{*} r / 2\right)$.

b) Then when the entrant enters with low cost, the payoff for the incumbent to defense the market is $\left(r-m^{*} C_{l}-C_{l}\right), m$ here is a scale parameter for the incumbent. The logic of $m$ is that if the incumbent takes an approach to defend the market, for example, reducing price, then the larger scale firm will be more affected. On the other hand, if the incumbent chooses acceptance, then the profit will be shared by them in line with the amount of investment, $\left(r^{*} C /\left(C+C_{l}\right), r^{*} C_{l} /\left(C+C_{l}\right)\right)$.

c) The last case is that the entrant decides not to enter, then the market will be dominated by the incumbent, thus he acquires all the market profit, $r$.

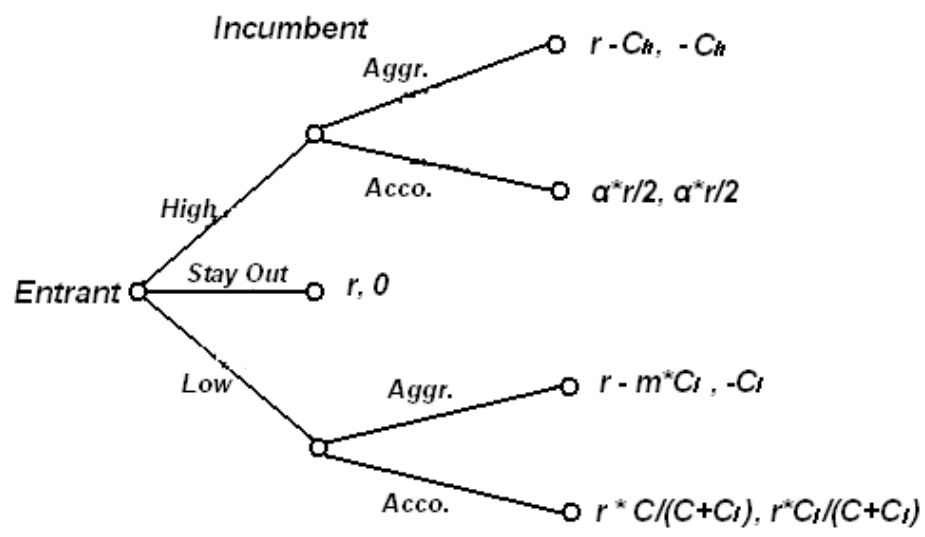

Fig. 1. The game tree of e-market entry game.

\section{Pure Strategy Equilibriums}

According to the game tree in previous section, all aggressive strategies with either high cost or low cost would not achieve the equilibrium because the entrant's payoffs are always negative. This means that the entrant has motivation to change the strategies and hence the equilibrium will get broken. There are three pure strategy asymmetric equilibriums in this game.

\subsection{Equilibrium of Entrant with High Cost}

When the entrant of high cost aims to achieve equilibrium, the corresponding equilibrium strategy is 
presented as: (enter with high cost, accommodation). In this case, both incumbent and entrant must get more profit than strategy (enter with high cost, aggressive). With this restrictive condition, the following inequalities must be satisfied:

$$
\left\{\begin{array}{l}
\alpha \times r / 2>r-C_{h} \\
\alpha \times r / 2>-C_{h}
\end{array}\right.
$$

These inequalities implies that both players will gain more profits if the strategy (enter with high cost, accommodation) is chosen in the game. With the calculation, the result of $C_{h}$ can be obtained as follows:

$$
C_{h}>(1-\alpha / 2) \times r
$$

This result reveals the fact the invest of entrant depending on the capacity of market and the adjusting parameter $\alpha$. More profitability the market has, more capital entrant should invest to guarantee the revenue. From (2), entrant spends more than half (depending on $\alpha$ ) profit of the market, can the incumbent accept the rival's entrance.

\subsection{Equilibrium of Entrants with Low Cost}

Same logic to first equilibrium, this equilibrium is constructed when the incumbent makes more profits by accepting than aggressing the entrant with low investment. As the game tree shows,

$$
\left\{\begin{array}{l}
r \times C /\left(C+C_{l}\right)>r-m \times C_{l} \\
r \times C /\left(C+C_{l}\right)>-C_{l}
\end{array}\right.
$$

Then we can get the condition of this equilibrium:

$$
C>C_{l}>(r-m \times C) / m
$$

As initially supposed, the investment of low cost entrant should be lower than that of incumbent which is assumed as $C$. Then the minimum of $C_{l}$ depends on $r, C$ and $m$. The value of $C_{l}$ rises when the capacity of profit $r$ increases as well as the scale parameter $m$ and incumbent's investment $C$ decrease.

\subsection{Equilibrium of the Entrant Staying out}

In the competition business world, staying out is always an option for e-retailers to choose. When the entrant does not have enough strength to enter with high cost, yet not meet the conditions of entering with low cost, the best choice of it will be staying out. The third equilibrium of this game is that the entrant does not enter into the market, the incumbent gains the whole market profit, $r$.

\section{Mixed Strategies Equilibriums}

As for the mixed strategy equilibriums, the high cost entrant and low cost entrant should be investigated respectively.

\subsection{For High Cost Entrant}

First, the entrant with high cost will be studied in this subsection. Setting the aggression probability as $x$ when the incumbent meet an entrant with high cost. Therefore, the probability of accommodation is (1-x). 


$$
\begin{gathered}
x \times\left(-C_{h}\right)+(1-x) \times(\alpha \times r / 2)=0 \\
x=\alpha \times r /\left(\alpha \times r+2 C_{h}\right)
\end{gathered}
$$

From the result of $x$ of (6), it is obvious that the aggression probability of incumbent principally depends on the investment of entrant. The more investments entrant makes, the more probability to be accepted by incumbent. The relationship between probability and investment can be analyzed by the following graph.

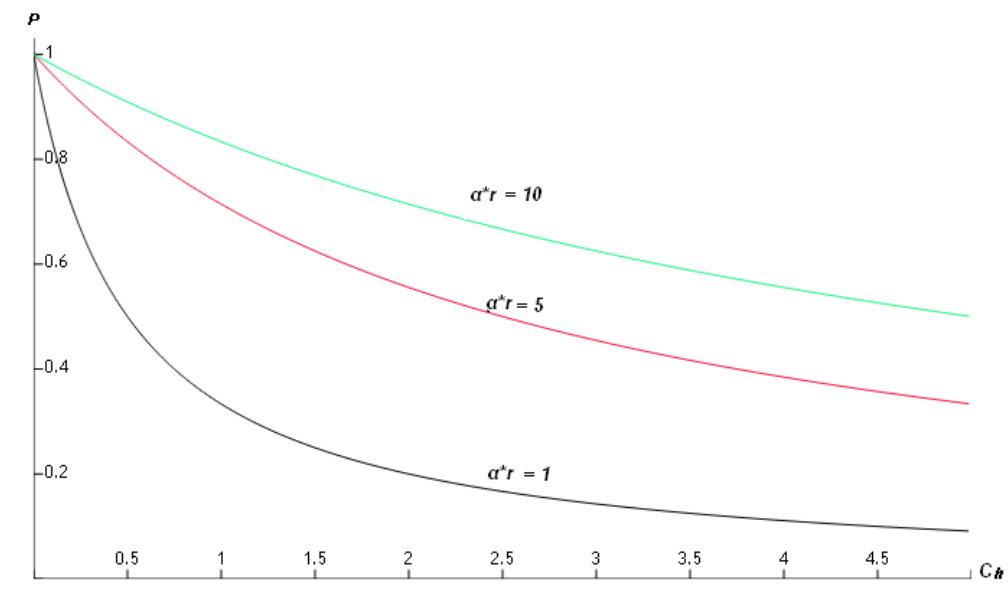

Fig. 2. The relationship between $P_{a g g r}$ and $C_{h}$ with different $r^{*} c$.

From Fig. 2, it can be seen that the trend of aggression decreases as the $C_{h}$ rises. When $C_{h}$ is small, the incumbent is more likely to be aggressive and drive it away from the market. Whereas when the $C_{h}$ is large enough, the cost of crowding out entrant is high for incumbent, thus it will accept the entrant.

Another phenomenon is that $\alpha \times r$ also influences the probability of aggression. When $\alpha \times r$ occupies small part in the equation, the $C_{h}$ will have a significant impact on probability, while $\alpha \times r$ increases, the influence of $C_{h}$ will decrease.

\subsection{For Low Cost Entrant}

When the entrant enters with low cost, the aggression probability of incumbent is defined as $y$, then probability of accommodation is (1-y). According to the payoff functions listed in game tree, the following equation is derived:

$$
y \times\left(-C_{l}\right)+(1-y) \times r \times C_{l} /\left(C+C_{l}\right)=0
$$

Calculating (7) and we finally get the expression of $y$ :

$$
y=r /\left(C+C_{l}+r\right)
$$

With the result of (8), the aggression probability of incumbent to compete with low cost entrant depends on the investment of incumbent $C$ and $C_{l}$. Let $k=C / C_{l}$ symbolize the difference between the incumbent and low cost entrant, the (8) could be transformed to :

$$
y=(r / C) /(k+1+r / C)
$$


With the (9), a figure is drawn to show the relations of aggression probability and the difference between the two competitors. The brief view of the figure gives us an indication that the probability of aggression is much lower than that in the high cost case. Then when the more the incumbent invests than the entrant, the lower probability it will aggress the entrant.

Another result is about $r / C$, which is the proportion of the profit and investment when the incumbent dominates the market. When the profitability of the market is higher, the incumbent determines to defend its market share.

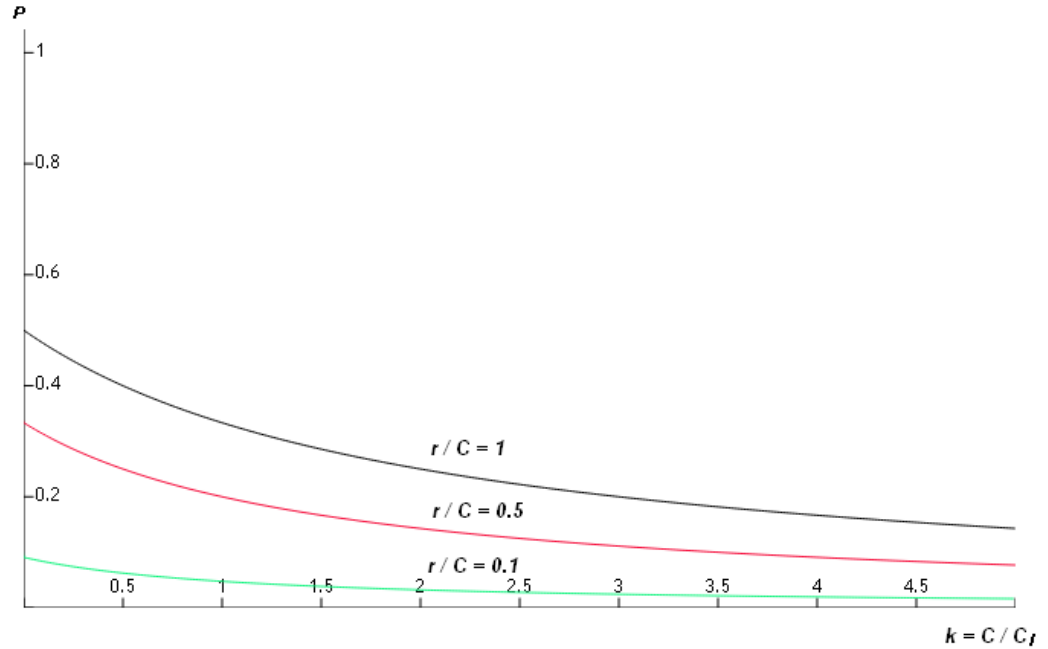

Fig. 3. The relationship between probability $P$ and difference between competitors $k$.

\section{Numerical Simulations}

In this section, the statistical method is employed to simulate the corresponding aggression probability of incumbents in every situation. First of all, high cost entrants and low cost entrants are divided into two categories, then various combinations of parameters are adopted to comprehensively analyze the probability of aggression. Finally, the hidden meaning can be deduced from the graphical demonstration.

\subsection{Probability of Aggression for High Cost Entrant}

As (6) shows, the probability is $x=(\alpha \times r) /\left(\alpha \times r+2 C_{h}\right)$. It depends on the adjusting parameter $\alpha$, capacity of the market $r$ and the investment of the high cost entrant $C_{h}$. To capture the relations between the probabilities of aggression of incumbent with these parameters, we conduct a statistical simulation experiment to show them in graph.

$\alpha$ is a variable which varies from a certain scale, for example, $(0,1)$ or $(0.5,1)$. This setup permits us to control the market capacity when competition becomes fierce. The existing of $\alpha$ makes the proposed model more similar to the real world.

From Fig. 4, we could find out that: a) When $\alpha$ changes within a big scale, like $(0,1)$, the probability of aggression is lower. This implies that when the competition is more drastic in a market, the profit varies significantly when entrants enter. This kind of market structure could be of the high-profitable category, custom-made service and monopoly industry. When the entrant enters into this market, the suggestion of the model is to enter with high cost and drag down the profit margin, which could decrease the aggression probability of incumbent, making sure that the firm gains benefit from entering into market.

b) The proportion of investment and profit is another important factor which could affect the aggression probability. It can be concluded from the figure that when $C_{h} / r$ changes within $(0,1)$, that means the $C_{h}$ could be lower than the profit. When the situation of investment is lower than profit, the incumbent is more motivated to protect profit. This leads to a high probability of aggression when facing the new entrant. 
While the investment equals profit, that means the investment payback maintains a low level, then the incumbent would invest less to aggress the entrant.

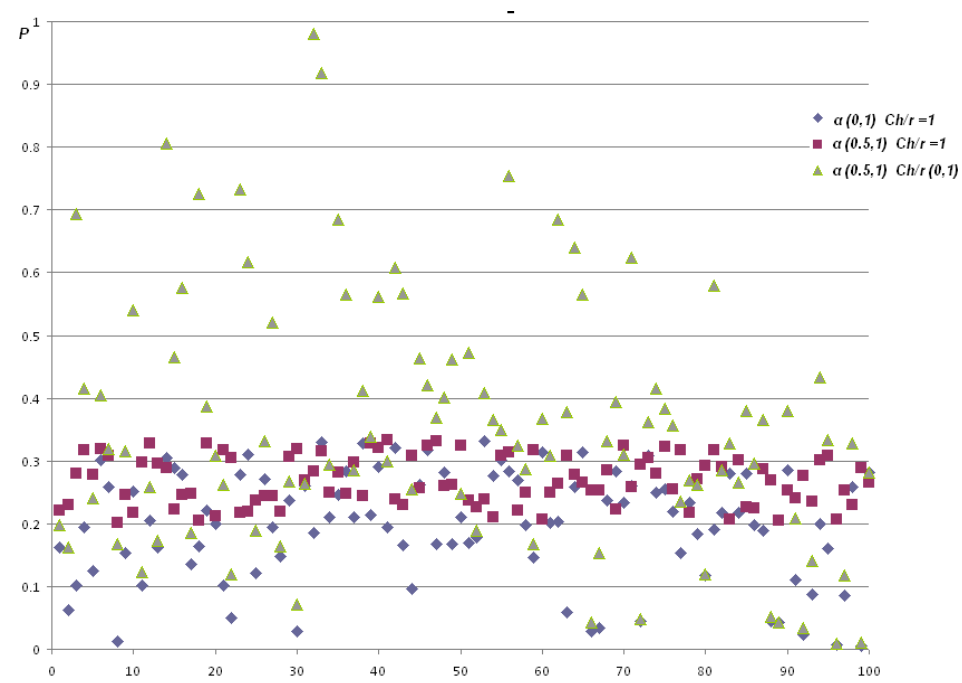

Fig. 4. Numerical simulation result between probability of aggression when high cost entrant enters into market.

\subsection{Probability of Aggregation for Low Cost Entrant}

As (9) shows, the probability is $y=(r / C) /(k+1+(r / C))$. It depends on the adjusting parameter, incumbent's investment $C$, difference between the incumbent and entrant $k$, and capacity of profit of market, $r$.

In simulation of low cost entrant, we fix the value of capacity of market $r=10$. But manipulate the parameters $C$ and $k$ in a $2 * 2$ factorial design, with $C$ assigning the values 3 and 6 , and $k$ assigning the values 5 and 10. The results in four different games are demonstrated in the following table 1 . The equilibrium probabilities $y^{*}$, are presented in column 4 of Table 1 .

Table 1. Probabilities of Low Cost Entrant in Four Different Situations

\begin{tabular}{cccc}
\hline$r$ & $C$ & $k$ & $y^{*}$ \\
\hline 10 & 3 & 5 & $35.71 \%$ \\
10 & 3 & 10 & $23.26 \%$ \\
10 & 6 & 5 & $21.74 \%$ \\
10 & 6 & 10 & $13.16 \%$ \\
\hline
\end{tabular}

From Table 1, we could figure out that: a) The probability of aggression by incumbent depends on the difference between the incumbent and entrant. When the difference of scale $k$ rises from 5 to 10 , the investment of incumbent increases higher than that of the entrant, the aggression probability declines rapidly from $35.71 \%$ to $23.26 \%$ when $C=3$, and from $21.74 \%$ to $13.16 \%$ when $C=6$. Fixing the incumbent's cost $C$, the entrant enters with lower investment. In this case, the probability of aggression is smaller by incumbent.

b) The probability of aggression by incumbent $y$ declines when incumbent's cost $C$ rises. It represents that the aggression probability is decreasing when the investment of incumbent is rising. The more the incumbent invests, the less possibility it aggresses. 


\section{Conclusion}

In this paper, an e-commerce entry game model is developed by extending game model of Selten and Güth [6]. The entrants are classified into two categories of low cost and high cost, each category corresponds to proper payoff function based on incumbent's choice. The incumbent could adopt the strategy between accommodation and aggression. The difference between these two strategies is that aggression will lead to loss in short period of time, while accommodation may bring loss in the long run.

Based on the game tree, the pure strategy equilibriums and mixed strategy equilibriums are studied respectively. Three pure strategy equilibriums are presented in section 3 and explicated detailedly. The mixed strategy equilibriums are analyzed and the probability of aggression by incumbent is researched and plotted graph in accordance with parameters.

According to the proposed model, the probability of aggression by incumbent is associated to entrant's strategy, adjusting parameter, and the difference of scale between the incumbent and entrant. For high investment entrant, incumbent is inclined to take the aggression strategy to defend the market; while for entrant with low investment, incumbent is benevolent to accommodate and share the market with it. The results of numerical simulations show the efficiency and correctness of the proposed model in this paper , the probability of aggression by incumbent could be an important factor to assist the decision-maker to act reasonably.

\section{Acknowledgment}

This research has been partially supported by the Coordination for the Improvement of Higher Education Personnel (CAPES) of Brazilian Ministry of Education.

\section{References}

[1] Dixit, A. (1989). Entry and exit decisions under uncertainty. Journal of Political Economy, 620-638.

[2] Hopenhayn, H. A. (1992). Entry, exit, and firm dynamics in long run equilibrium. Econometrica: Journal of the Econometric Society, 1127-1150.

[3] Impullitti, G., Irarrazabal, A. A., \& Opromolla, L. D. (2013). A theory of entry into and exit from export markets. Journal of International Economics, 90(1), 75-90.

[4] Shen, Q. (2014). A dynamic model of entry and exit in a growing industry. Marketing Science, 33(5), 712-724.

[5] Gries, T., Prior, U., \& Sureth, C. (2012). A tax paradox for investment decisions under uncertainty. Journal of Public Economic Theory, 14(3), 521-545.

[6] Selten, R., \& Güth, W. (1982). Equilibrium point selection in a class of market entry games. Games, Economic Dynamics, and Time Series Analysis (pp. 101-116).

[7] Aguirregabiria, V., \& Suzuki, J. (2014). Identification and counterfactuals in dynamic models of market entry and exit. Quantitative Marketing and Economics, 12(3), 267-304.

[8] Rapoport, A. (1995). Individual strategies in a market entry game. Group Decision and Negotiation, 4(2), 117-133.

[9] Zwick, R., \& Rapoport, A. (2002). Tacit coordination in a decentralized market entry game with fixed capacity. Experimental Economics, 5(3), 253-272.

[10] Azevedo, A., \& Paxson, D. (2014). Developing real option game models. European Journal of Operational Research, 237(3), 909-920.

[11] Zheng, J. Y., Daniel, L. Z. L., Li, W. G., Zhang, Z. K., Xu, H. B. (2014). E-commerce game model — Balancing platform service charges with vendor profitability. 613-619. 


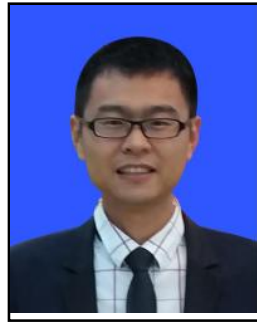

data mining.

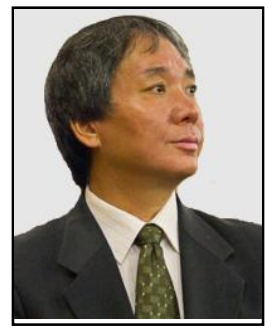

Zheng Jianya received his B.Sc. in computer science from Northeastern University of China in 2006, and M.Sc. of informatics in 2012 from the University of Brasilia (UnB), Brazil.

He is a Ph.D candidate of TransLab in the Department of Computer Science of UnB. His study is supported by the PhD fellowship from the Coordination for the Improvement of Higher Education Personnel (CAPES) of Brazilian Ministry of Education.

Mr. Zheng's research interests include electronic commerce, online social network and

Li Weigang received the Ph.D. degree from the Aeronautics Institute of Technology (ITA), São José dos Campos, Brazil, in 1994.

$\mathrm{He}$ is currently an associate professor and a coordinator of TransLab with the Department of Computer Science, University of Brasilia (UnB), Brasilia, Brazil.

Dr. Li is coordinating the cooperation project between Boeing and UnB from 2015 to 2018. His research interests include artificial intelligence, with emphasis on web information systems, data mining and computation model in air traffic flow management. 